\title{
Age-dependent safety analysis of propofol-based deep sedation for ERCP and EUS procedures at an endoscopy training center in a developing country
}

\author{
This article was published in the following Dove Press journal: \\ Clinical and Experimental Gastroenterology \\ 6 July 2012 \\ Number of times this article has been viewed
}

\author{
Somchai Amornyotin ${ }^{1,2}$ \\ Somchai Leelakusolvong ${ }^{2,3}$ \\ Wiyada Chalayonnawin ${ }^{1,2}$ \\ Siriporn Kongphlay ${ }^{1,2}$ \\ 'Department of Anesthesiology, \\ ${ }^{2}$ Siriraj GI Endoscopy Center, \\ ${ }^{3}$ Department of Medicine, Faculty of \\ Medicine, Siriraj Hospital, Mahidol \\ University, Bangkok, Thailand
}

\begin{abstract}
Introduction: Endoscopic retrograde cholangiopancreatography (ERCP) and endoscopic ultrasonography (EUS) procedures in elderly patients are on the rise, and they play an important role in the diagnosis and management of various gastrointestinal diseases. The use of deep sedation in these patients has been established as a safe and effective technique in Western countries; however, it is uncertain if the situation holds true among Asians. The present study aimed to evaluate the age-dependent safety analysis and clinical efficacy of propofol-based deep sedation (PBDS) for ERCP and EUS procedures in adult patients at a World Gastroenterology Organization (WGO) Endoscopy Training Center in Thailand.
\end{abstract}

Methods: We undertook a retrospective review of anesthesia or sedation service records of patients who underwent ERCP and EUS procedures. All procedures were performed by staff endoscopists, and all sedations were administered by anesthesia personnel in the endoscopy room.

Results: PBDS was provided for 491 ERCP and EUS procedures. Of these, 252 patients (mean age, $45.1 \pm 11.1$ years, range 17-65 years) were in the $<65$ age group, 209 patients (mean age, $71.7 \pm 4.3$ years, range $65-80$ years) were in the $65-80$ year-old group, and 30 patients (mean age, $84.6 \pm 4.2$ years, range $81-97$ years) were in the $>80$ age group. Common indications for the procedures were pancreatic tumor, cholelithiasis, and gastric tumor. Fentanyl, propofol, and midazolam were the most common sedative drugs used in all three groups. The mean doses of propofol and midazolam in the very old patients were relatively lower than in the other groups. The combination of propofol, midazolam, and fentanyl, as well as propofol and fentanyl, were frequently used in all patients. Sedation-related adverse events and procedure-related complications were not statistically significantly different among the three groups. Hypotension was the most common complication.

Conclusion: In the setting of the WGO Endoscopy Training Center in a developing country, PBDS for ERCP and EUS procedures in elderly patients by trained anesthesia personnel with appropriate monitoring is relatively safe and effective. Although adverse cardiovascular events, including hypotension, in this aged group is common, all adverse events were usually transient, mild, and easily treated, with no sequelae.

Keywords: deep sedation, propofol, endoscopic retrograde cholangiopancreatography, endoscopic ultrasonography, elderly, developing country

\section{Introduction}

The use of endoscopic retrograde cholangiopancreatography (ERCP) and endoscopic ultrasonography (EUS) procedures in geriatric patients is rising as a result of population 
demographics and the developing application of technology to clinical problems. Considering these changes, ERCP and EUS procedures play an important role in the delivery of gastrointestinal healthcare. The proportion of these patients is increasing, and a high number of geriatric patients undergoing gastrointestinal endoscopies (GIE) have been observed. ${ }^{1-3}$ Although concerns remain regarding the safety and potential benefits of endoscopies, previous studies have shown that ERCP and EUS procedures can be safe and well tolerated, even in very old patients. ${ }^{4-7}$ One significant factor in performing better tolerated endoscopies is the use of intravenous sedation.

ERCP and EUS procedures are invasive procedures that produce moderate to severe pain, and most are performed using deep sedation. Sedation in elderly patients requires awareness of their increased response to sedative agents. A multiplicity of physiological processes contributes to the increase in sensitivity and sedation risk in elderly patients. ${ }^{8}$ When sedating the geriatric patient, the agent of choice should have a high potency and short half-life, with minimal active metabolites and limited side effects. Midazolam, fentanyl, and propofol are the common sedative agents used for moderate to deep sedation. These sedatives have a reduced clearance in elderly patients.

We conducted a retrospective study to evaluate the agedependent safety analysis and clinical efficacy of propofolbased deep sedation (PBDS) for ERCP and EUS procedures in adult patients at a World Gastroenterology Organization (WGO) Endoscopy Training Center in Thailand.

\section{Methods}

\section{Patients}

This retrospective study, performed on a convenience sample of consecutive subjects, was conducted from September 2007 to February 2009, at Siriraj GI Endoscopy Center, Faculty of Medicine, Siriraj Hospital, Mahidol University. All patients were classified into three groups according to age. In group A, the patients were younger than 65 ; in group $B$, the patients were 65-80 years old; and the patients in group $\mathrm{C}$ were older than 80 . The inclusion criteria included patients who underwent ERCP and EUS procedures with PBDS technique during the study period. Exclusion criteria included patients with severe hemodynamic and respiratory instabilities, full stomach cases, morbid obesity, and patients younger than 17 years old.

\section{Endoscopy-related procedure}

ERCP and EUS procedures were performed by staff endoscopists. All endoscopies were conducted with an
Olympus video endoscope compatible with the type of the GIE procedure. After completion of the GIE procedure, the patients were admitted to the recovery room for at least two hours to rule out immediate post-endoscopic complications. The patients then were admitted to the ward for at least 24 hours to monitor for other complications. Procedurerelated complications were defined according to the British Society of Gastroenterology. ${ }^{9}$

\section{Sedation-related procedure}

Appropriate monitoring was used for all patients who underwent PBDS. Cardiovascular monitoring included continuous electrocardiogram, heart rate measurements, and oxygen saturation measurements, as well as noninvasive blood pressure measurements taken at five-minute intervals with a cuff device. Ventilation monitoring included continuous respiratory rate measurements and interval observation of respiration patterns, chest movement, and signs and symptoms of airway obstruction. Level of consciousness was also periodically assessed. End-tidal carbon dioxide monitoring with capnography was not used during sedation.

The sedative agents used were dependent upon the patient's medical condition and the familiarity of the anesthesiologist with the particular case. All patients were oxygenated with $100 \% \mathrm{O}_{2}$ via nasal cannula and sedated by well-trained anesthesia personnel directly supervised by a staff anesthesiologist in the endoscopy room. Anesthesia personnel included residents in anesthesiology and anesthesia nurses who were well trained in the use of intravenous sedation techniques and airway management. All patients were sedated at a deep sedation level, according to guidelines of the American Society of Anesthesiologists ${ }^{10}$ and the American Society of Gastrointestinal Endoscopy. ${ }^{11}$ Complications, such as hypotension, bradycardia, hypoxia $\left(\mathrm{SpO}_{2}<90 \%\right)$, and airway obstruction, were recorded. Serious adverse events were defined as prolonged desaturation or apnea lasting more than 20 seconds.

\section{Statistical analysis}

Results are expressed as mean (SD), median, or percentage $(\%)$, as appropriate. Comparisons of overall sedationrelated adverse events and procedure-related complications among the three different groups were conducted with a one-way analysis of variance (ANOVA) $F$-test. The statistical software package SPSS for Windows (version 11; SPSS Inc, Chicago, IL) was used to analyze the data. A significance level of 0.05 was used throughout the study. 
Table I Characteristics of patients, sedation time, and indications of procedures

\begin{tabular}{|c|c|c|c|}
\hline & Group A & Group B & Group C \\
\hline Number of patients (\%) & $252(5 \mid .3)$ & $209(42.6)$ & $30(6.1)$ \\
\hline Age (years) (SD) & $45.1(11.1)$ & $71.7(4.3)$ & $84.6(4.2)$ \\
\hline \multicolumn{4}{|l|}{ Sex (\%) } \\
\hline Male & $116(46.0)$ & $109(52.2)$ & 14 (46.7) \\
\hline Female & $136(54.0)$ & $100(47.8)$ & $16(53.3)$ \\
\hline Weight (kg) (SD) & $55.6(9.1)$ & $53.8(9.1)$ & $49.3(7.3)$ \\
\hline \multicolumn{4}{|l|}{ ASA physical status (\%) } \\
\hline I & $164(65.1)$ & $2(1.0)$ & 0 \\
\hline II & $78(31.0)$ & $160(76.6)$ & $16(53.3)$ \\
\hline III & $10(4.0)$ & $46(22.0)$ & $14(46.7)$ \\
\hline IV & 0 & $\mathrm{I}(0.5)$ & 0 \\
\hline Sedation time (min) (SD) & $47.3(20.3)$ & $51.2(30.9)$ & $43.2(25.0)$ \\
\hline \multicolumn{4}{|l|}{ Indications of procedure (\%) } \\
\hline Cholelithiasis & $26(10.3)$ & $38(18.2)$ & $9(30.0)$ \\
\hline Pancreatitis & $8(3.2)$ & $22(10.5)$ & $16(16.7)$ \\
\hline Gastric tumor & $42(16.7)$ & $32(15.3)$ & $4(13.3)$ \\
\hline Pancreatic tumor & $85(33.7)$ & $42(20.1)$ & $3(10.0)$ \\
\hline Hepatobiliary abnormality & $38(15.1)$ & $28(13.4)$ & $3(10.0)$ \\
\hline Abdominal pain & $21(8.3)$ & $4(1.9)$ & 0 \\
\hline Others & $32(12.7)$ & $43(20.6)$ & $6(20.0)$ \\
\hline
\end{tabular}

Notes: Group A: age $<65$ years; group B: age $65-80$ years; group C: age $>80$ years.

\section{Results}

During the study period, 491 patients who underwent ERCP and EUS procedures with a PBDS technique were reviewed; 252 (51.3\%) were in group A, 209 (42.6\%) were in group B, and $30(6.1 \%)$ were in group C. The characteristics of the study population are shown in Table 1; there were no differences in weight or sedation time among the three groups. The gender breakdown in groups $\mathrm{A}$ and $\mathrm{C}$ were comparable, but group B had a relatively higher rate of male patients than did groups A and C. Indications for procedures also are summarized in Table 1 . The majority of pre-sedation problems were hypertension, hematologic diseases, and diabetes mellitus. All sedation was concluded with the satisfactory completion of the procedure.

The mean doses of the sedative agents, categorized by age and ASA physical status, are shown in Tables 2 and 3, respectively. Propofol, midazolam, and fentanyl were the most common sedative agents used in all three groups. The mean doses of propofol and midazolam were significantly higher in group A than in the other two groups. In addition, mean doses of propofol, midazolam, and fentanyl in the patients with ASA III-IV were not significantly different.

Table 4 shows the combinations of sedative agents used in all three groups. Most of the sedative agents were used in combination with two or three other agents. The combination of propofol, midazolam, and fentanyl was the most common combination of sedative agents used in all three groups $(86.1 \%, 84.7 \%, 76.7 \%)$.

Overall, respiratory- and cardiovascular-related adverse events, as well as procedure-related complications, were comparable in all three groups. The majority of the sedationrelated adverse events were cardiovascular, including hypotension. Respiratory-related adverse events were rare. All of the adverse events, in all three groups, were transient and handled under the care of an anesthesiologist. No procedures were aborted as a result of insufficient sedation or complications of PBDS. Subsequently, procedure-related complications occurred in two patients in Group A and one patient in Group B (Table 5).

Table 2 Mean dose of sedative agents categorized by age

\begin{tabular}{|c|c|c|c|}
\hline & $\begin{array}{l}\text { Group A } \\
(252)\end{array}$ & $\begin{array}{l}\text { Group B } \\
(209)\end{array}$ & $\begin{array}{l}\text { Group C } \\
(30)\end{array}$ \\
\hline \multicolumn{4}{|l|}{ Propofol } \\
\hline$n(\%)$ & $252(100.0)$ & $209(100.0)$ & $30(100.0)$ \\
\hline $\mathrm{mg} / \mathrm{kg} / \mathrm{hr}$ & $6.3(2.5), 2.5-18.3$ & 5.0 (2.7), I.0-18.5 & $4.0(1.6), 1.8-9.2$ \\
\hline \multicolumn{4}{|l|}{ (SD, range) } \\
\hline \multicolumn{4}{|l|}{ Fentanyl } \\
\hline n (\%) & $237(94.0)$ & $200(95.7)$ & $28(93.3)$ \\
\hline $\mathrm{mg} / \mathrm{kg} / \mathrm{hr}$ & $0.00 \mathrm{I}(0.00 \mathrm{I}), 0.000-0.006$ & $0.00 I$ (0.00I), $0.000-0.008$ & $0.00 \mathrm{I}(0.00 \mathrm{I}), 0.000-0.004$ \\
\hline \multicolumn{4}{|l|}{ (SD, range) } \\
\hline \multicolumn{4}{|l|}{ Pethidine } \\
\hline$n(\%)$ & II (4.4) & $5(2.4)$ & 0 \\
\hline $\mathrm{mg} / \mathrm{kg} / \mathrm{hr}$ & $0.7(0.3), 0.2-1.2$ & $0.7(0.5), 0.4-1.5$ & \\
\hline \multicolumn{4}{|l|}{ (SD, range) } \\
\hline \multicolumn{4}{|c|}{ Midazolam } \\
\hline$n(\%)$ & 231 (9I.7) & $186(89.0)$ & $25(83.3)$ \\
\hline $\mathrm{mg} / \mathrm{kg} / \mathrm{hr}$ & $0.05(0.04), 0.01-0.36$ & $0.03(0.02), 0.00-0.19$ & $0.03(0.03), 0.01-0.15$ \\
\hline (SD, range) & & & \\
\hline
\end{tabular}

Notes: Group A: age $<65$ years; group B: age $65-80$ years; group C: age $>80$ years. 
Table 3 Mean dose of sedative agents categorized by ASA physical status ( $\mathrm{mg} / \mathrm{kg} / \mathrm{hr}$, SD, range)

\begin{tabular}{|c|c|c|c|c|c|c|}
\hline & \multicolumn{3}{|l|}{ ASA I-II } & \multicolumn{3}{|l|}{ ASA III-IV } \\
\hline & $\begin{array}{l}\text { Group A } \\
(242)\end{array}$ & $\begin{array}{l}\text { Group B } \\
(162)\end{array}$ & $\begin{array}{l}\text { Group C } \\
(16)\end{array}$ & $\begin{array}{l}\text { Group A } \\
(10)\end{array}$ & $\begin{array}{l}\text { Group B } \\
\text { (47) }\end{array}$ & $\begin{array}{l}\text { Group C } \\
(14)\end{array}$ \\
\hline \multirow[t]{2}{*}{ Propofol } & $6.3(2.6)$ & $5.3(2.6)$ & $4.5(2.0)$ & $5.6(2.1)$ & $4.3(2.8)$ & $3.8(1.4)$ \\
\hline & $2.5-18.3$ & $1.4-16.0$ & $1.8-9.2$ & $2.5-10.5$ & $1.0-18.5$ & $1.8-6.3$ \\
\hline \multirow[t]{2}{*}{ Fentanyl } & $0.001(0.001)$ & $0.001(0.001)$ & $0.001(0.00 I)$ & $0.001(0.001)$ & $0.001(0.001)$ & $0.002(0.001)$ \\
\hline & $0.000-0.006$ & $0.000-0.008$ & $0.000-0.004$ & $0.000-0.002$ & $0.000-0.007$ & $0.000-0.004$ \\
\hline \multirow[t]{2}{*}{ Pethidine } & $0.7(0.3)$ & $0.7(0.5)$ & 0 & 0 & 0 & 0 \\
\hline & $0.3-1.2$ & $0.4-1.5$ & & & & \\
\hline \multirow[t]{2}{*}{ Midazolam } & $0.05(0.04)$ & $0.03(0.02)$ & $0.03(0.04)$ & $0.04(0.02)$ & $0.04(0.04)$ & $0.04(0.02)$ \\
\hline & $0.01-0.36$ & $0.00-0.11$ & $0.01-0.15$ & $0.02-0.09$ & $0.01-0.19$ & $0.01-0.07$ \\
\hline
\end{tabular}

Notes: Group A: age $<65$ years; group B: age $65-80$ years; group C: age $>80$ years.

Abbreviation: ASA, American Society of Anesthesiologists.

\section{Discussion}

The present study shows that PBDS for ERCP and EUS procedures is relatively safe and effective, even in elderly patients. Our observations confirm and extend the previous studies. ${ }^{3-5,12}$ When we compared the results to the younger patients investigated within the same time period, an obvious trend toward more invasive procedures with a therapeutic objective was seen in the very old patients. All endoscopic procedures were able to be completed. Our report of PBDS practice in elderly patients showed that it can be conducted safely in various sedative combinations, with proper monitoring and anesthesiology service supervision.

ERCP and EUS procedures are invasive and of long duration, and ERCP procedures can produce abdominal pain. ${ }^{13}$ Deep sedation and general anesthesia techniques are commonly used for these procedures, unlike colonoscopy procedures, which are conducted with mild to moderate sedation. However, general anesthesia techniques for ERCP and EUS procedures in elderly patients are not routinely used. ${ }^{1,2,7}$ All general anesthetic drugs can be used, but the dose should be carefully and patiently adjusted, according to the response. Generally, more elderly patients will need much lower doses than younger patients. ${ }^{14}$ The major disadvantage of general anesthesia is the increased time, which limits the number of complex endoscopic procedures that can be performed. It takes time to induce anesthesia,

Table 4 Combination of sedative agents used (n, \%)

\begin{tabular}{llll}
\hline & $\begin{array}{l}\text { Group A } \\
\mathbf{( 2 5 2 )}\end{array}$ & $\begin{array}{l}\text { Group B } \\
\mathbf{( 2 0 9 )}\end{array}$ & $\begin{array}{l}\text { Group C } \\
\mathbf{( 3 0 )}\end{array}$ \\
\hline Propofol-pethidine & $\mathrm{I}(0.4)$ & 0 & 0 \\
Propofol-midazolam & $4(1.6)$ & $4(1.9)$ & $2(6.7)$ \\
Propofol-fentanyl & $20(7.9)$ & $23(11.0)$ & $5(16.7)$ \\
Propofol-midazolam-fentanyl & $217(86.1)$ & $177(84.7)$ & $23(76.7)$ \\
Propofol-midazolam-pethidine & $10(4.0)$ & $5(2.4)$ & 0 \\
\hline
\end{tabular}

Notes: Group A: age $<65$ years; group B: age $65-80$ years; group C: age $>80$ years. perform a tracheal intubation, position the patient, reverse muscle relaxants, and perform tracheal extubation. Sedative drugs used in elderly patients should have a short half-life, with minimally active metabolites and limited side effects. The modification in sedation practice required in these patients is administration of fewer agents at a slower rate and with a lower cumulative dose. Lower initial doses of sedatives - usually half the normal recommended adult dose - along with slow and continuing titration to effect, is a useful guide when sedating elderly patients. ${ }^{8}$

Midazolam and narcotics are generally used, as in younger patients. Fentanyl, which has a short half-life and rapid onset of action, may have an advantage over pethidine in geriatric patients. Propofol has a narrower margin of safety; however, it has been shown to be safe when used in elderly patients. ${ }^{12,15,16}$ It is known to lower blood pressure in young and old patients alike. ${ }^{17}$ Propofol, combined with short-acting benzodiazepine, with or without fentanyl, has already been used in several endoscopic procedures. Moreover, propofol is easy to use, has a good safety and efficacy profile due to its quick onset of action and significantly shorter recovery time, and it has some anti-emetic effects. ${ }^{17,18}$ The amount of sedation required depends on the patient's physical status and the type of endoscopic procedure. The combination of propofol, midazolam, and fentanyl is commonly used in our center.

The present study used only standard monitoring, including an assessment of blood pressure, pulse rate, respiratory rate, pulse oximetry, and electrocardiogram. We believe that the appropriate selection of patients for sedation is very important and will most likely reduce the rate of adverse events. The use of pulse oximetry to monitor hypoxemia is important, especially in cases when supplemental oxygen is administered. Our study showed a relatively high overall rate of adverse events, in about $32 \%-36 \%$ of the procedures. 
Table 5 Sedation-related adverse events and procedure-related complications (n, \%)

\begin{tabular}{|c|c|c|c|c|}
\hline & $\begin{array}{l}\text { Group A } \\
(252)\end{array}$ & $\begin{array}{l}\text { Group B } \\
\text { (209) }\end{array}$ & $\begin{array}{l}\text { Group C } \\
\text { (30) }\end{array}$ & $P$ value \\
\hline Overall & $83(32.9)$ & $69(33.0)$ & II (36.7) & 0.917 \\
\hline Respiratory & $8(3.2)$ & $6(2.9)$ & I (3.3) & 0.978 \\
\hline Hypoxia $\left(\mathrm{SpO}_{2}<90 \%\right)$ & $3(1.2)$ & $2(1.0)$ & 0 & 0.823 \\
\hline Upper airway obstruction & $5(2.0)$ & $4(1.9)$ & I (3.3) & 0.873 \\
\hline Cardiovascular & $73(29.0)$ & $62(29.7)$ & $10(33.3)$ & 0.883 \\
\hline Hypotension & $66(26.2)$ & $56(26.8)$ & $10(33.3)$ & 0.706 \\
\hline Hypertension & $2(0.8)$ & $3(1.4)$ & 0 & 0.672 \\
\hline Bradycardia & $4(1.6)$ & $3(1.4)$ & 0 & 0.786 \\
\hline Arrhythmia & I (0.4) & 0 & 0 & 0.622 \\
\hline Procedure-related & $2(0.8)$ & I (0.5) & 0 & 0.826 \\
\hline Duodenal perforation & 0 & I (0.5) & 0 & 0.509 \\
\hline Hemorrhage & I (0.4) & 0 & 0 & 0.622 \\
\hline Pancreatitis & I (0.4) & 0 & 0 & 0.622 \\
\hline
\end{tabular}

Notes: Group A: age $<65$ years; group B: age 65-80 years; group C: age $>80$ years.

This rate is higher than what is commonly reported, for which there may be several explanations. We used these criteria in defining adverse events: hypo/hypertension and brady/ tachycardia measured as changes in blood pressure and heart rate, respectively, of more than $25 \%$ of baseline values. Hypoxia was defined as oxygen saturation $<90 \%$.

Data from our previous study showed that patient and endoscopist satisfaction in sedated patients was higher than in non-sedated patients. ${ }^{19}$ The use of sedation was the major determinant of patient satisfaction and willingness to repeat the procedure. However, sedation contributed to an increased adverse event rate and increased recovery room time. Propofol is commonly used for deep sedation; however, the combination of low-dose propofol and other sedative agents can shorten the recovery period and, thus, is suitable for endoscopic procedures. In our previous study, we found that sedation-related adverse events were significantly lower with diluted propofol than with undiluted propofol. ${ }^{16}$ However, only undiluted propofol was used in this study. In addition, we have used deep sedation extensively for invasive endoscopic procedures, such as ERCP and EUS, in our hospital, and the indications and contraindications for PBDS in geriatric patients are the same as in younger adult patients.

Finally, this study shows that PBDS for ERCP and EUS procedures in elderly patients in a WGO Endoscopy Training Center in a developing country can be performed safely and effectively. We believe that this success is due to two factors: dedicated anesthesia service involved with the sedation and the use of basic non-invasive monitoring, which includes non-invasive blood pressure monitoring, pulse oximetry, and electrocardiogram. This practice is different from the practices of provincial and community hospitals, where most invasive endoscopic procedures are performed in the operating room, with the use of general anesthesia techniques. Methodology, data, and results from a developing country such as ours will help underscore the importance of basic monitoring to the success of deep sedation in elderly patients undergoing ERCP and EUS procedures outside the operating room, particularly in the endoscopy unit.

This study has some limitations. First, we encountered some inaccurate and incomplete documentation of certain measures, as occurs with many chart reviews. Second, there is a wide range of ASA physical statuses, pre-sedation problems, and indications of the procedure in our study. Drug requirements, recovery time, and adverse effects can be related to these factors. Third, our practice employed only basic monitoring, which does not include the use of end-tidal carbon dioxide for ventilation monitoring. Thus, adverse respiratory events may have been underestimated. However, in a place with limited resources for monitoring, such as Thailand, we relied heavily on the clinical assessments. ${ }^{20}$ Overall, despite these limitations, we are confident that PBDS for ERCP and EUS procedures in elderly patients can be performed safely and effectively.

\section{Conclusion}

Herein, we report the age-dependent safety analysis and clinical experience of PBDS for ERCP and EUS procedures in adult patients at a WGO Endoscopy Training Center in Thailand. The findings of the present study also showed that adverse cardiovascular events in elderly patients are common. However, all adverse events were of a mild degree and usually transient, as well as easily treated, 
with no sequelae. In addition, this study showed that these procedures can safely and effectively be performed in elderly patients outside the operating room, with a multi-drug sedative regimen, utilizing anesthesiologists or anesthesia personnel with appropriate basic monitoring.

\section{Disclosure}

The authors report no conflicts of interest in this work.

\section{References}

1. Kerker A, Hardt C, Schlief HE, Dumoulin FL. Combined sedation with midazolam/propofol for gastrointestinal endoscopy in elderly patients. BMC Gastroenterol. 2010;10:11.

2. Umegaki E, Abe S, Tokioka S, et al. Risk management for gastrointestinal endoscopy in elderly patients: questionnaire for patients undergoing gastrointestinal endoscopy. J Clin Biochem Nutr. 2010;46(1): 73-80.

3. Amornyotin S, Srikureja W, Pausawasdi N, Prakanrattana U, Kachintorn U. Intravenous sedation for gastrointestinal endoscopy in very elderly patients of Thailand. Asian Biomed. 2011;5(4):485-491.

4. Clarke GA, Jacobson BC, Hammett RJ, Carr-Locke DL. The indications, utilization and safety of gastrointestinal endoscopy in an extremely elderly patient cohort. Endoscopy. 2001;33(7):580-584.

5. Amornyotin S, Kachintorn U, Chalayonnavin W, Kongphlay S. Propofolbased deep sedation for endoscopic retrograde cholangiopancreatography procedure in sick elderly patients in a developing country. Ther Clin Risk Manag. 2011;7:251-255.

6. Jafri SM, Monkemuller K, Lukens FJ. Endoscopy in the elderly: a review of the efficacy and safety of colonoscopy, esophagogastroduodenoscopy, and endoscopic retrograde cholangiopancreatography. J Clin Gastroenterol. 2010;44(3):161-166.

7. Benson ME, Byrne S, Brust DJ, et al. EUS and ERCP complication rates are not increased in elderly patients. Dig Dis Sci. 2010;55(11): 3278-3283.

8. Qureshi WA, Zuckerman MJ, Adler DG, et al. ASGE guideline: modifications in endoscopic practice for the elderly. Gastrointest Endosc. 2006;63(4):566-569.
9. Green J. Complications of gastrointestinal endoscopy. BSG Guidelines in Gastroenterology. British Society of Gastroenterology; Nov 2006:1-30. Available from: http://www.bsg.org.uk/pdf_word_docs/complications. pdf. Accessed February 8, 2012.

10. American Society of Anesthesiologists Task Force on Sedation and Analgesia by Non-Anesthesiologists. Practice guidelines for sedation and analgesia by non-anesthesiologists. Anesthesiology. 2002;96(4): 1004-1017.

11. Faigel DO, Baron TH, Goldstein JL, et al. Guidelines for the use of deep sedation and anesthesia for GI endoscopy. Gastrointest Endosc. 2002;56(5):613-617.

12. Riphaus A, Stergiou N, Wehrmann T. Sedation with propofol for routine ERCP in high-risk octogenarians: a randomized, controlled study. Am J Gastroenterol. 2005;100(9):1957-1963.

13. Amornyotin S, Phasurin T, Wongnuch P. Pain score within twentyfour hours post-endoscopic retrograde cholangiopancreatography: a comparison between diagnostic and therapeutic procedures. Gastroenterol Insights. 2009;1(e7):20-23.

14. Steinmetz J, Rasmussen LS. The elderly and general anesthesia. Minerva Anestesiol. 2010;76(9):745-752.

15. Amornyotin S, Chalayonnavin W, Kongphlay S. Propofol-based sedation does not increase rate of complication during percutaneous endoscopic gastrostomy procedure. Gastroenterol Res Pract. Epub August 3, 2010.

16. Amornyotin S, Srikureja W, Chalayonnavin W, Kongphlay S. Dose requirement and complications of diluted and undiluted propofol for deep sedation in endoscopic retrograde cholangiopancreatography. Hepatobiliary Pancreat Dis Int. 2011;10(3):313-318.

17. Heuss LT, Inauen W. The dawning of a new sedative: propofol in gastrointestinal endoscopy. Digestion. 2004;69(1):20-26.

18. Tramer M, Moore A, McQuay H. Propofol anesthesia and postoperative nausea and vomiting: quantitative systemic review of randomized controlled studies. Br J Anaesth. 1997;78(3):247-255.

19. Amornyotin S, Lertakayamanee N, Wongyingsinn M, Pimukmanuskit P, Chalayonnavin W. The effectiveness of intravenous sedation in diagnostic upper gastrointestinal endoscopy. J Med Assoc Thai. 2007; 90(2):301-306.

20. Amornyotin S, Chalayonnawin W, Kongphlay S. Deep sedation for endoscopic retrograde cholangiopancreatography: a comparison between clinical assessment and Narcotrend ${ }^{\mathrm{TM}}$ monitoring. Med Devices: Evid Res. 2011;4:43-49.
Clinical and Experimental Gastroenterology

\section{Publish your work in this journal}

Clinical and Experimental Gastroenterology is an international, peerreviewed, open access journal, publishing all aspects of gastroenterology in the clinic and laboratory, including: Pathology, pathophysiology of gastrointestinal disease; Investigation and treatment of gastointestinal disease; Pharmacology of drugs used in the alimentary tract;

\section{Dovepress}

Immunology/genetics/genomics related to gastrointestinal disease. This journal is indexed on CAS. The manuscript management system is completely online and includes a very quick and fair peer-review system. Visit http://www.dovepress.com/testimonials.php to read real quotes from published authors. 